VARIA 


\section{As mulheres, no começo da história}

Regina Zilberman
PUC-RS

Mulber é desdobrável.

Adélia Prado

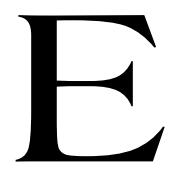

laborado nos anos 80, do século XX, o estudo de Ria Lemaire sobre as cantigas de amigo ${ }^{1}$ contribui de modo vigoroso para uma revisão na historiografia das literaturas em língua portuguesa. Aceita a tese de que, dentre os textos remanescentes da lírica medieval pertencente àquele gênero poético, constam os que se originaram de manifestação feminina, coletiva e anônima, textos esses depois apropriados por "autores" homens que se limitaram a transcrevêlos e adaptá-los ao gosto vigente, anexando seu nome a eles, cabe igualmente creditar a mulheres o começo, ou ao menos um dos inícios, da literatura lusófona.

Ria Lemaire considera as cantigas de amigo um discurso "à voix féminine ${ }^{2}$ remontando à tradição da lírica amorosa praticada por mulheres, "poesia de oralidade primária", ${ }^{3}$ que circulava entre outras

\footnotetext{
${ }^{1}$ Fidelino de Figueiredo assim define os cantares de amigo: eles "simulam ser compostos por mulheres, que contam as suas dores de amor". (FIGUEIREDO, 1966. p. 72). Na História da literatura portuguesa, escrevem António José Saraiva e Óscar Lopes: "A diferença entre as cantigas de amor e as de amigo consiste (...) em que nestas se supõe que fala uma mulher, ao passo que naquelas o trovador fala em seu próprio nome." (SARAIVA e LOPES, [s. d.], p. 44).

${ }^{2}$ LEMAIRE, 1987. p. 95.

${ }^{3}$ LEMAIRE, 1987. p. 272.
} 
manifestações orais, como as de cunho épico, masculina e guerreira. A lírica feminina, aparentemente, dispunha de grande circulação na Alta Idade Média, contando com uma audiência em que não se distinguiam produtor e destinatário, já que todos/todas podiam participar solidariamente dos atos de criação e recepção. Correspondia, pois, a uma elaboração comunitária, cujo emissor exprimia sua perspectiva, feminina, ativa e plena de desejo amoroso.

Os poemas, localizáveis em coletâneas como o Cancioneiro da Ajuda, organizado por Carolina Michaelis de Vasconcelos, nos começos do século XX, apresentam características singulares, que, conforme sugere Ria Lemaire, nunca mais se repetiram na literatura:

- originalmente de circulação oral, eram formulados por mulheres, que traduziam sua perspectiva, mas não se identificavam, preferindo o anonimato e a dispersão na comunidade;

- os versos equivalem a "expressões variadas evocando uma jovem ativa, que toma iniciativas no domínio do amor e exprime, sob diversas formas, seu desejo, um 'desejar' ativo que se torna uma 'exigência' concreta"; ${ }^{4}$

- quando da recitação dos poemas, "a recepção da mensagem é direta e faz-se com o concurso das faculdades humanas corporais, intelectuais, espirituais e afetivas. O fator corporal é primordial: mover-se com os outros, cantar com os outros, é: experimentar/pensar com os outros."

Provavelmente a pesquisadora idealiza as condições de produção e circulação desses poemas. Seu intuito é valorizar um material de procedência popular e oral, na medida em que atribui a ele qualidades raras, e depois praticamente desaparecidas, no que se refere à temática e ao relacionamento entre criador e público. Assim, se, nesses poemas, se sobressai a perspectiva feminina, esta não se apresenta de modo dominador, e sim igualitário:

Pode-se ter certeza de que, se, nas suas canções, as mulheres tomam iniciativas, se elas se representam como sujeitos locutores/focalizadores/atores em posição autônoma e se elas exigem do homem a

\footnotetext{
${ }^{4}$ LEMAIRE, 1987. p. 183.

5 LEMAIRE, 1987. p. 275.
} 
mesma posição enquanto sujeito, este é o mesmo comportamento que era estimado e estimulado para os dois sexos na realidade da vida cotidiana. ${ }^{6}$

Além disso, como se observou acima, os poemas não apenas envolvem a audiência de modo integral, mas igualmente supõem que o corpo inteiro participe, sem discriminações entre os sujeitos, nem, sobretudo, entre a parte - a beleza, a alma - e o todo, supondo a generalidade do indivíduo. Conforme acentua a pesquisadora, o poeta, que é também o compositor e intérprete, interage com o grupo graças à autoridade dada pela "tradição oral subjacente", que, "permanecendo oculta durante a performance, está ao mesmo tempo onipresente, já que conhecida de todos e reconhecida imediatamente pelos membros da comunidade, que a conservam na memória." " Para reforçar a tese, a autora compara as cantigas de amigo à cansò, de procedência francesa, cuja autoridade provém do texto escrito e cujo intérprete não coincide mais com o compositor, determinando dois tipos de clivagem: entre o criador e o cantor; e entre esse último e a audiência, reduzida à passividade da escuta.

Ainda que se possa relativizar o entusiasmo da pesquisadora pela matéria que examina, de procedência popular e oral, por parecerem idealizadas as circunstâncias de produção - por exemplo, a suposta igualdade de gênero entre os parceiros e a cogitada ausência de divisões sociais -, não se negam nem a qualidade dos versos, nem o fator histórico: essas canções constituem o berço da lírica em língua portuguesa, que nasceu em diapasão feminino.

Em outro trabalho, Ria Lemaire transcreve um dos poemas que conteriam as qualidades que advoga, canção que se reproduz a seguir, conforme versão e ortografia propostas pela pesquisadora:

Que coita tamanha ei a sofrer por amar amigu'e non o veer! e pousarei so lo avelãal.

Que coita tamanha ei a endurar por amar amigu'e non lhi falar! e pousarei so lo avelãal.

${ }^{6}$ LEMAIRE, 1987. p. 295.

7 LEMAIRE, 1987. p. 272. 
Por amar amigu, e non o veer, nen lh'ousar a coita que ei dizer: e pousarei so lo avelãal.

Por amar amigu'e non lhi falar, nem lh'ousar a coita que ei mostrar: e pousarei so lo avelãal.

Nen lh'ousar a coita que ei dizer e non mi dan seus amores lezer: e pousarei so lo avelãal.

Nen lh'ousar a coita que ei mostrar e non mi dan seus amores vagar: e pousarei so lo avelãal. ${ }^{8}$

O poema constrói-se conforme o modelo canônico, em paralelo, marcado pela repetição do último verso de cada estrofe. ${ }^{9}$ Em cada uma dessas estrofes, aparece a palavra-chave do poema, coita, significando não apenas "pena, dor, aflição", este sendo o registro atual dos dicionários, mas, conforme enfatiza Ria Lemaire, "desejo ativo, incluindo alegria e sofrimento", ${ }^{10}$ o que evidencia o posicionamento atuante e exigente do sujeito que enuncia os versos.

Esse sujeito é, sem dúvida, uma mulher, que participa a falta do companheiro, ausência que impede a concretização do desejo. A locutora apresenta-se em primeira pessoa desde o verso inicial, manifestando vontade própria e iniciativa: quer ver e falar com o amigo, provavelmente dar a conhecer sua coita e, para tanto, dirige-se à aveleira, espaço erotizado que traduz seu anseio e aspiração à realização amorosa.

O sujeito lírico é, pois, não apenas o locutor, mas também ator, não se colocando em posição subalterna ou passiva: ver o amigo não é suficiente, sendo igualmente importante o falar, o dizer e o mostrar, ações características de um indivíduo ágil e pleno de iniciativas. Nada que corresponda, portanto, à imagem de uma dama inerte ou apática, colocada

${ }^{8}$ O poema está transcrito em LEMAIRE, 1986, p. 742.

9 Relativamente à estrutura-padrão das cantigas de amigo, cf. SARAIVA e LOPES, [s. d.], p. 45-47.

${ }^{10}$ SARAIVA e LOPES, [s. d.]. p. 731. 
na situação de quem aguarda o empreendimento alheio, seja este a conquista ou o culto, perspectiva com que a mulher veio a ser entendida na lírica medieval posterior. ${ }^{11}$

Assim, mesmo supondo que os versos reproduzidos acima tenham sido registrados por um autor homem, há que reconhecer que, neles, a ótica feminina é mais do que evidente, porque ninguém, a não ser uma mulher, expressaria seu desejo por um companheiro nos termos ali propostos. Esse desejo, por um vez, não se revela debilitado ou castrado; pelo contrário, ele materializa-se por intermédio de formas carregadas de erotismo, como a palavra "coita" originalmente supõe e a figura da "avelãal" corporifica. Da sua parte, o emprego da primeira pessoa acentua a circunstância de se expressar o sentimento do locutor, indivíduo dotado de querer e empreendedor, que não se submete a uma ordem ou a uma proibição.

A ausência da interdição parece ser o traço mais original do poema: o sujeito lírico não confessa a coita ao parceiro, por este encontrar-se distante ou por ela carecer de ousadia, conforme os verso 8, 11, 13 e 16, nas terceira, quarta, quinta e sexta estrofes respectivamente. E, se a falta de ousadia pode parecer sintoma de fragilidade ou encolhimento perante a atitude do amigo, vale observar que a palavra se contrapõe, fônica e semanticamente, ao "pousarei", que introjeta o "ousar" e supera-o, razão, aliás, da cota de erotismo que a aveleira carrega consigo.

Eis por que o sujeito lírico parece corresponder a uma mulher livre e independente, que não hesita em declarar publicamente seu amor e apetite - igualmente figurado pela aveleira - sexual.

O contexto em que tal expressão poderia se manifestar não fica estabelecido pelo poema. O cenário esclarece pouco, porque os versos são bastante econômicos, centrando a informação no sentimento do sujeito lírico, interessado em patentear suas carências - a do amigo distante, a quem não vê -, bem como a vontade de saciar o desejo, exibindo a ele a coita de que está acometida.

A falta de informações relativamente ao contexto deve-se, provavelmente, à circunstância de ser esse conhecido de falante e ouvintes, seja por vivenciá-lo - hipótese sugerida por Ria Lemaire -, seja por pertencer às convenções desse gênero de poesia, já de resto bastante

${ }^{11}$ Cf. LAPA, 1952, p. 57; SARAIVA e LOPES, [s. d.], p. 57; SPINA, 1966. 
atento às regras de composição, conforme sugerem as reiterações e paralelismos. Tal ausência, por sua vez, leva a supor que se trata de uma sociedade em que os papéis sexuais estariam distribuídos de modo igualitário, sendo a mulher, no caso, a porta-voz dessa paridade.

Como se localizam os poemas nos séculos XI/XII da era cristã, a igualdade teria sido experimentada então ou antes. Se não na prática, pelo menos imaginariamente, a ponto de a poesia poder expressá-la, de um modo como, no Ocidente, ainda não acontecera. Depois, instalaram-se as clivagens e as dominações, por força da necessidade de se estabelecer uma ordem familiar e política centrada num sujeito, no caso, o homem, o pater familias e proprietário, a quem se subordinaram mulheres, descendentes, agregados, vassalos. Dependentes de um poder superior, esses sujeitos perderam a voz, de que resultou uma poesia que fala em seu nome, mas não em primeira pessoa, muito menos de modo autosuficiente.

A perda da voz traduziu-se em mais de uma maneira: não apenas o sujeito lírico mudou de lugar, falando de um outro - o amante que lamenta a ausência do ser amado - ou manifestando o penar de que é objeto, e neste caso renunciando à atitude empreendedora e autônoma de antes. Correspondeu igualmente à mudança de registro: a oralidade foi substituída pelo escrita, sendo essa transformação um dos importantes instrumentos de dominação desde então utilizados.

Com efeito, a difusão da escrita enquanto instrumento político dissemina-se a partir do século XII. Se, no Ocidente, foram os gregos da Antigüidade que a utilizaram primeiramente para consignar propriedades, contabilizar lucros ou testemunhar o pesar pela perda de entes queridos, em monumentos tumulares, ${ }^{12}$ depois para registrar epopéias, diálogos filosóficos e dramas trágicos, no que foram sucedidos pelos latinos, na Idade Média, essa atividade restringiu-se aos religiosos, que se valiam da escrita para anotar acontecimentos ou para explicitar reflexões, narrar suas memórias memórias e declarar atos de constrição.

A partir do século XII, são os chefes de Estado que recorrem à escrita para garantir a durabilidade de seu poder e a eficiência da administração pública. Jean Hébrard assinala que data desse período a instalação de chancelarias e escritórios aos quais competia registrar os atos

${ }^{12}$ Cf. SVENBRO, 1993. 
do governo. ${ }^{13}$ E Maria José Azevedo Santos observa que, em Portugal, foi com D. Afonso II, que subiu ao trono em 1211, que se estabilizaram cargos como os de notários, tabeliães e escrivães, profissionais responsáveis pela credibilidade e legitimidade dos documentos públicos, primeiramente reais, a seguir, da população em geral. ${ }^{14}$

Registros das canções remontariam a esse período e depois, mas, na passagem do oral para o escrito, outras alterações ocorreram:

- emerge a figura do autor, muitas vezes sucessor do copista responsável pela transcrição da fala;

- desaparece a perspectiva feminina auto-suficiente, transformada em sujeito passivo, ou por lamentar uma ausência impossível de ser satisfeita, ou por se apresentar na posição de pessoa a ser cultuada, sem, contudo, propiciar a proximidade física, menos ainda o contato sexual.

No transcurso do processo de fixação pela escrita, dar-se-ia a domesticação da mulher, correspondendo à situação experimentada por ela na vida social, ao menos entre os grupos superiores. De sujeito ela se torna objeto, de criadora, converte-se em audiência. ${ }^{15}$ As cantigas de amigo perdem a naturalidade original, tornando-se um caso entre outros de poesia medieval.

$\mathrm{Na}$ interpretação de Ria Lemaire, a historiografia da literatura portuguesa endossou o processo histórico. Exceção feita a Carolina Michaelis, cuja pesquisa, contudo, permaneceu inacabada, os pesquisadores voltados ao estudo da lírica galaico-portuguesa assumiram a perspectiva masculina com que passaram à tradição: nas cantigas de amigo, os versos, de autoria masculina, traduziriam a pena experimentada por uma mulher, ao perceber-se distanciada do amado distante. A vOZ feminina, suprimida uma vez pelos copistas, é de novo cassada, pois nem mesmo os estudiosos do assunto interessaram-se em valorizar o que estaria por trás e antes do material transportado do passado: a locução feminina, a perspectiva da mulher, o caráter popular e coletivo dessas manifestações, um caso raro de permanência de um estágio diferenciado da produção

\footnotetext{
${ }^{13}$ Cf. HÉBRARD, 2000.

${ }^{14}$ Cf. SANTOS, 2000.

${ }^{15}$ Cf. LEMAIRE, 1986.
} 
artística do Ocidente, aquele em que se fundem o indivíduo e a comunidade, o criador e o público, o sujeito e o objeto.

As expressões mais libertárias da lírica galaico-portuguesa passariam pelo processo de domesticação que as inseria ao discurso da dominação da mulher.

Desse processo talvez a história das literaturas lusófonas tenha de se penitenciar.

A proposta de redimensionamento do lugar das cantigas de amiga nessa historiografia parece ser um bom começo. Se se reconhecer o papel que a mulher desempenha em sua produção - e não se trata de lhe atribuir a autoria, pois, na perspectiva da Alta Idade Média, esse conceito não se aplica, sendo ele produto da modernidade, posterior à implantação e difusão da imprensa,$-{ }^{16}$ admitir-se-á igualmente a função fundadora que ela ocupa na trajetória histórica. Porque as cantigas de amigo parecem preceder os demais estilos abrigados sob a denominação de lírica galaicoportuguesa; além disso, mostram-se mais autênticas, já que independem da interferência da lírica provençal, paradigma de grande ascendência sobre a produção das cantigas de amor.

Por último e não menos importante, as cantigas de amigo parecem ter estabelecido seus próprios paradigmas, que doravante impulsionarão fortemente a poesia portuguesa, pelo menos até o Renascimento, no século XVI, quando padrões petrarquistas serão adotados por Sá de Miranda, Antônio Ferreira e Luís de Camões. Depois, românticos, como Almeida Garrett, e modernos, como Fernando Pessoa, foram atrás deles, pesquisando-os, embora provavelmente ignorando sua origem popular, oral e feminina. ${ }^{17}$ Com isso, perdeu-se o elo da origem, passível de ser recuperado, colocando em posição pioneira mulheres medievais, apaixonadas e capazes de expressar seus sentimentos de modo livre e autêntico, a ponto de abrirem mão da identidade e do nome.

${ }^{16}$ Cf. a respeito CHAMARAT, 1996; LAJOLO e ZILBERMAN, 2001.

${ }^{17}$ A respeito do Romanceiro, de Almeida Garrett, cf. LEMAIRE, 1987. 


\section{Referências Bibliográficas}

CHAMARAT, Gabrielle. Introduction. In: COLLOQUE DE CERISY-LA-SALLE (4-8 Ocotobre 1995). L'auteur. Actes publiés sous la direction de Gabrielle Chamarat e Alain Goulet. Caen: Presses Universitaires de Caen, 1996.

FIGUEIREDO, Fidelino. História literária de Portugal. São Paulo: Nacional, 1966.

HÉBRARD, Jean. Por uma bibliografia material das escrituras ordinárias. A escritura pessoal e seus suportes. In: MIGNOT, Ana Chrystina Venancio; BASTOS, Maria Helena Camara; CUNHA, Maria Teresa Santos (Org.). Refúgios do eu. Educação, história, escrita autobiográfica. Florianópolis: Mulheres, 2000 .

LAJOLO, Marisa e ZILBERMAN, Regina. O preço da leitura. Leis e números por detrás das letras. São Paulo: Ática, 2001.

LAPA, M. Rodrigues. Lições de literatura portuguesa. Época medieval. 3. ed. revista e acrescentada. Coimbra: Coimbra, 1952.

LEMAIRE, Ria. Passions et positions. Contribution à une sémiotique du sujet dans la poésie lyrique médiévale en langues romanes. Amsterdam: Dodopi, 1987.

LEMAIRE, Ria. Explaining away the female subject: the case of medieval lyric. Poetics Today, v. 7:4, 1986, p. 729-743.

SANTOS, Maria José Azevedo. Ler e compreender a escrita na Idade Média. Coimbra: Edições Colibri; Faculdade de Letras de Coimbra, 2000.

SARAIVA, António José e LOPES, Óscar. História da literatura portuguesa. 4. ed. Porto: Porto, [s. d.].

SPINA, Segismundo. Do formalismo estético trovadoresco. São Paulo: Faculdade de Filosofia, Ciências e Letras da Universidade de São Paulo, 1966.

SVENBRO, Jesper. Phrasikleia. An Anthropology of Reading in Ancient Greece. Ithaca and London: Cornell University Press, 1993. 


\section{Resumo}

Estudo das cantigas de amigo a partir da constatação de que estas estabelecem paradigmas próprios que impulsionarão a poesia portuguesa do Renascimento aos modernos.

\section{Résumé}

Etude des "cantigas-de-amigo", à partir de la constatation suivante: ces chansons établient certains paradigmes propres qui vont relancer la poésie portugaise de la Renaissance jusqu'aux modernes. 